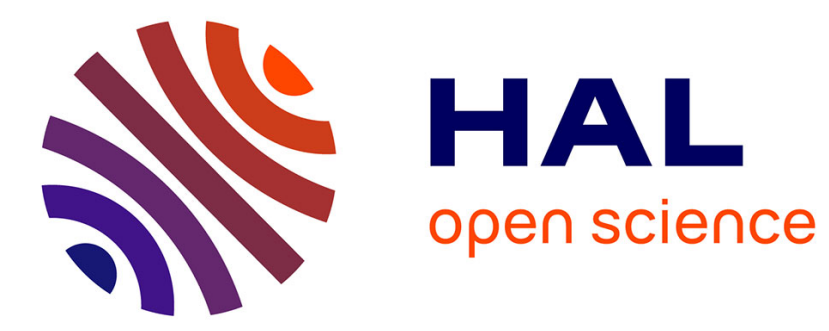

\title{
Venous thrombosis in patients with high-grade glioma
}

\author{
Sophie Taillibert, Luc Taillandier, Emilie Le Rhun
}

\section{To cite this version:}

Sophie Taillibert, Luc Taillandier, Emilie Le Rhun. Venous thrombosis in patients with high-grade glioma. Current Opinion in Oncology, 2015, 27 (6), pp.516-521. 10.1097/CCO.0000000000000226 . hal-01288625

\section{HAL Id: hal-01288625 \\ https://hal.sorbonne-universite.fr/hal-01288625}

Submitted on 15 Mar 2016

HAL is a multi-disciplinary open access archive for the deposit and dissemination of scientific research documents, whether they are published or not. The documents may come from teaching and research institutions in France or abroad, or from public or private research centers.
L'archive ouverte pluridisciplinaire HAL, est destinée au dépôt et à la diffusion de documents scientifiques de niveau recherche, publiés ou non, émanant des établissements d'enseignement et de recherche français ou étrangers, des laboratoires publics ou privés. 


\section{VENOUS THROMBOSIS IN PATIENTS WITH HIGH-GRADE GLIOMA}

Sophie Taillibert ${ }^{1}$ (MD), Luc Taillandier ${ }^{2}$ (MD, PhD), Emilie Le Rhun ${ }^{3}$ (MD).

\section{Affiliations:}

1.Neurologie 2 Department- Pitié-Salpétrière Hospital- Paris VI Pierre and Marie Curie University- Assistance Publique des Hôpitaux de Paris- Paris, France.

2.Neuro-oncology Unit, Neurooncology Department. Nancy University Hospital- Central Hospital and CRAN UMR 7039 CNRS, SBS BEAM department, Nancy

University,Vandœuvre-lès-Nancy.France.

3. Neuro-oncology Department, University Hospital, Lille, France; Medical Oncology Department, Oscar Lambret Center, Lille, France and INSERM U1192, PRISM laboratory, Lille University, Villeneuve d'Ascq, Laboratoire PRISM, France, France

\section{Corresponding author:}

Dr Sophie TAILLIBERT

Neurologie 2 Department-

Pitié-Salpétrière Hospital -

47-83 bd de 1'hôpital, 75013, Paris, France.

Tel: +33(0)142164160

Fax: +33 (0)1 42160418

Email: sophie.taillibert@psl.aphp.fr-

sophie.taillibert@gmail.com 


\section{ABSTRACT}

Purpose of review:

High-grade glioma (HGG) patients are at particularly high risk of venous thromboembolism

(VTE) occurrence and recurrence. VTE is associated with worsened survival in these patients. Currently, the main challenge when prescribing anticoagulants in HGG patients is to address the risk of intracranial hemorrhage (ICH) and provide the optimal treatment.

Recent findings:

Here, we discuss the latest biological findings and their potential implications for better classification in daily practice and stratification of patients in future trials according to their risk of developing a VTE.

Summary:

To help clinicians, international guidelines have been provided for cancer patients, but their implementation remains suboptimal. We report here the specificities of VTE management in HGG patients relative to other cancer patients. Particular aspects such as anticoagulation under targeted therapies, primary and secondary prophylaxis and the role of new oral anticoagulants are discussed as well.

KEYWORDS:

Deep venous thrombosis, pulmonary embolism, high-grade glioma, brain tumor, glioblastoma 
Word count:

Abstract: 143

Text: 2503 
List of abbreviations:

BT Brain Tumor

CNS Central Nervous System

GBM Glioblastoma

GTR Gross Total Resection

HGG High Grade Glioma

INR International Normalized Ratio

LMWH Low Molecular Weight Heparin

MPs Microparticles

NS Not Significant

RAM risk assessment model

TF Tissue Factor

TF-MPs Tissue Factor Microparticles

VEGF vascular endothelial growth factor

VKA Vitamin K Antagonist

VTE Venous Thromboembolism 


\section{INTRODUCTION}

High-grade glioma (HGG) patients display one of the highest relative risks of VTE among cancer patients, with observed rates as high as 25-39\% (1-3). VTE is associated with worsened survival in glioblastoma (GBM) patients (3). The main concern when prescribing a prophylactic or curative antithrombotic treatment in HGG patients is the risk of intracranial hemorrhage ( $\mathrm{ICH})$. In this review, we discuss the epidemiology, currently identified risk factors, and therapeutic management of VTE in HGG patients. Specific situations such as treatment of VTE occurring under anti-VEGF therapy, primary and secondary prophylaxis and the role of new oral anticoagulants are discussed as well. 


\section{EPIDEMIOLOGY:}

The incidence rates have been most frequently described within a range of 7.5 to $39 \%$, with the lowest rate reported in a retrospective assessment, thus probably underestimated, and rates of $17-18 \%$ observed in recent prospective studies with a diagnosis based on a combination of clinical and ultrasound-Doppler assessments (1-7). Even if the probability of VTE occurrence is particularly high in the post-operative period, with nearly half of the events occurring at that time, the risk persists throughout the course of the disease, with rates between $7 \%$ and $28 \%$ over a 12 month period. (1-2,8-13). A recent retrospective study reported that $22.2 \%$ of the unplanned readmissions of GBM patients within 30 days of surgery were related to VTE (14). These patients had twice the risk of mortality compared with other patients. 


\section{RISK FACTORS:}

Among many identified risk factors that can be divided into patient-related, tumor-related, treatment-related, leg motor impairment seems the most consistently reported, with a relative risk for VTE between 2.6 and $3.6(10,12,15-16)$. The other patient-related, identified, preoperative, independent factors include poor Karnofsky Performance Scale (KPS) scores, older age ( $\geq 65$ Y.O, especially $>75$ Y.O) $(6,10,15)$, elevated body mass index (17), hypertension (10), hemoglobin (17) and A or AB blood type (18). Tumor-related factors include a higher grade $(\mathrm{GBM}>$ WHO grade 3 glioma $>$ WHO grade 2 glioma $)(10,12)$, larger size $(>5 \mathrm{~cm})$ $(11,18)$ and recurrent disease. The role of intraluminal thrombosis remains controversial $(19-$ 21). Treatment-related risk factors include the extent of surgical resection (biopsy $>$ partial $>$ gross total resection $<$ GTR $>$ ) (17), surgery duration $>4$ hours (22), recent neurosurgery $(<2$ months), chemotherapy (8) and anti-VEGF agents $(19,23)$. D-dimer elevation above 0.865 $\mathrm{mg} / \mathrm{l}$ and/or hemiparesis was factors found to predict a VTE 4 weeks before its clinical outcome in GBM patients under bevacizumab (24).

\section{IDENTIFICATION OF PREDICTIVE BIOMARKERS}

A recent study identified the following biomarkers in HGG patients: platelet count, D-dimers, sP-Selectin, FVIII activity, prothrombin fragment 1+2, and leukocyte count (25). Only the first 3 parameters have been confirmed in multivariate analyses. Platelet count was inversely correlated with VTE risk, which is a completely new observation that differs from previous studies on other malignancies that report a high platelet count as a risk factor (26). A low platelet count with high sP-selectin put patients at high risk of post-surgery VTE $(83.3 \%)$ (25). A risk assessment model (RAM) based on low platelet count $\left(<25^{\text {th }}\right.$ percentile), high leukocyte count and increased D-dimers ( $\geq 75^{\text {th }}$ percentile) was also used. The patients scoring 
2 or 3 were considered at high risk (37.7\%) of developing VTE, while patients scoring 0 were at low risk $(3.3 \%)$ of developing the disease. Further validation of these data is needed. High levels of FVIII, a validated risk-factor for VTE (27), were already previously found to be predictive of VTE in HGG patients (28) They may be caused by tumor-mediated cytokine release, vascular injury and surgical disruption of the blood-brain barrier. 


\section{BIOLOGY OF VTE IN BRAIN TUMORS}

The coagulation system is continually activated in GBM, where intratumoral vaso-occlusive thrombosis may trigger hypoxia, pseudopalisading necrosis, and angiogenesis.

Tissue Factor (TF) has been shown to be constitutively overexpressed in glioma, and thus has been suggested to play a central role in the pathogenesis of VTE (8). An increased expression or activity of TF in glioma has been previously associated with glioma grade (29), craniotomy (13), tumor hypoxia (30-31), VEGF expression (32), PTEN mutation/loss (30-31) and EGFR amplification (33). The prothrombotic action of circulating microparticles (MPs), in which TF derived from glioma cells is present, remains controversial (34-36). Nevertheless, circulating MP levels have been shown to diminish after completion of chemoradiotherapy, and MP activity may be superior in the case of greater residual tumor burden (34). A better understanding of the TF pathway and its effect on HGG behavior and microenvironment is essential to define the exact role of anticoagulants in BT management. 


\section{VTE RISK ASSESSMENT AND PROPHYLAXIS OF VTE}

Because the benefit of prophylaxis increases with the risk of VTE, improved prediction of the risk is crucial. A periodic assessment of VTE risk, based on a validated assessment tool has been recommended in cancer patients (37-40).

It is commonly accepted that hospitalized patients who have an active malignancy with an acute medical illness or reduced mobility should receive pharmacologic thromboprophylaxis in the absence of contra-indications (41-44). This recommendation applies to HGG patients. The decision to initiate prophylactic anticoagulation with low molecular weight heparin (LMWH) in patients suffering from intratumoral bleeding complicated by functional impairment and immobilization should be discussed on a case-by-case basis. This decision should rely on the evaluation of the benefit /risk ratio between worsening of the bleeding and the occurrence of a VTE.

During the peri-operative period, the administration of LMWH or unfractionated heparin in combination with mechanical methods, such as pneumatic compression stockings, appears to be effective and reduces risk of postoperative VTE by $50 \%$ at least (45). This method is safe and does not cause any increased risk of major ICH despite a 2-fold higher rate of minor bleeding $(4,45-48)$. Nevertheless, safety has been shown under the condition that anticoagulation is started within 24 hours after surgery because the risk of clinically significant ICH has been shown to be increase if anticoagulants are initiated before neurosurgery $(46,49)$. This timing is specific to neurosurgical patients $(37,41)$. In cancer patients, the minimal advised duration of the post-surgical primary prophylaxis is at least between 7 and 10 days. However, in the case of prolonged immobilization or restricted 
mobility caused by functional impairment, prophylactic anticoagulation should be prolonged until ambulation is recovered. A combination of mechanical and pharmacologic prophylaxis is advised because it improves the efficacy of treatment in high-risk patients $(41,45,50)$. It remains uncertain whether the HGG patients could benefit from an extended post operative prophylaxis, like in the case of high risk cancer patients to whom 4 weeks are advised (41). Further investigations are required.

Outside of the peri-operative period and hospitalization, long- term prophylactic anticoagulation is not recommended due to a lack of available data in the literature To assess this specific situation, the PRODIGE trial was designed to evaluate the potential role of LMWH (dalteparin) in GBM patients and specifically detect a reduction in TVE-free survival at 6 months (51). A total of 186 patients were randomized into 2 groups of treatment (dalteparin vs. placebo) until the premature termination of the trial was caused by a shortage of the placebo. Dalteparin was administered during a minimum period of 6 months, which could be extended to a total of 12 months. A lack of power may explain why statistical significance was not present despite the difference observed between the 2 groups in terms of clinically relevant VTE incidence (11\% with dalteparin vs. 17\% with placebo). At 12 months, the incidence of major ICH was higher in the dalteparin group (5\% vs. $1 \%$, NS), with one fatal ICH. Two phase II studies addressed this question in HGG patients.

In the ECOG study, also interrupted prematurely, 45 patients received dalteparin during a median time of 6.3 months without any occurrence of VTE or ICH (52).

In another study, tinzaparin was assessed in 40 patients. A $2.5 \%$ rate of VTE and of ICH was observed after median treatment duration of 5 months (53). 
A controlled, randomized, triple-blind, multinational phase III study is planned and will assess the role of the oral factor X blocker apixaban over a 12-month-period in newly diagnosed GBM. The primary endpoint is overall survival (54).

No data support the safety and efficacy of the use of aspirin in the long-term prophylaxis of TVE in patients with HGG, and consequently, this approach cannot be advised (55). 


\section{TREATMENT OF SYMPTOMATIC VTE}

There is no standardized approach for the management of HGG patients suffering from a VTE because most existing international guidelines address cancer patients in general. Here, we discuss the specificities characterizing the management of such patients.

\section{Bleeding-risk assessment}

Although the anticoagulation of VTE at a curative dosage appears to be safe in most HGG patients, a pre-assessment of the risk of bleeding and its consequences in terms of neurological worsening is advised to establish the expected risks and benefits prior to any treatment decision $(8,56)$. This risk is considerably different according to the histological type of the tumor, natural past history of bleeding and the nature of the concomitant anticancer treatment administered to the patient. In HGG, the reported risk of spontaneous hemorrhage is typically between $2 \%$ and $8 \%$, with higher rates in GBM, and anaplastic oligodendroglioma $(15,57-58)$.

\section{Contra-indications to anticoagulation and indications of inferior vena cava filters}

Preexisting post-surgical intraparenchymal blood products in asymptomatic patients do not contra-indicate anticoagulant use for documented symptomatic VTE (59). Anticoagulation at curative doses should be avoided in the case of recent significant intratumoral symptomatic bleeding, thrombopenia under 50000 platelets $/ \mathrm{mm}^{3}$, and for any other usual contraindication such as coagulopathy $(37,41)$. When anticoagulants cannot be prescribed at curative doses, the insertion of inferior vena cava (IVC) filters is a possible option, despite a known high rate of complications that include up to a $40 \%$ rate of recurrent VTE, filter thrombosis, and post-thrombotic syndrome (60). In addition, physicians should be 
aware that caution should be applied in patients with recent brain surgery, those at high risk for falls, and those who are expected to show poor compliance to treatment, especially in the case of oral medication (41). Unfortunately, all of these mentioned situations are frequent in the population of neuro-oncology patients due to sensory-motor, visual, balance and cognitive deficits.

\section{Which anticoagulant?}

According to several retrospective and prospective series, LMWH appears to be safe in the curative setting in patients with HGG $(1,60)$. LMWH does not interact with other drugs frequently prescribed for BT patients and does not require any frequent monitoring for therapeutic activity. The efficacy of LMWH was superior to that of VKAs with no increased risk of ICH in the CLOT trial (61).

In HGG patients, several retrospective series have shown an acceptable profile of tolerance for warfarin without any significant increase in the risk of $\mathrm{ICH}$ under the conditions that the International Normalized Ratio (INR) remains in the therapeutic range and that the perioperative period is avoided $(15,55,62)$. As a matter of fact, the careful monitoring of the INR needed to maintain warfarin in the therapeutic range is difficult to implement in the daily practice because INR variations are subject to many interactions with chemotherapy, steroids and some antiepileptic drugs. These variations expose patients to risks of both TVE recurrence (infratherapeutic range) and $\mathrm{ICH}$ (supratherapeutic range) and thus consequently to the discomfort of very frequent laboratory blood sampling to evaluate the INR. New oral anticoagulants, such as direct inhibitors of thrombin or factor Xa, have not been evaluated in this specific population, and one should be aware of the absence of an antidote in the case of a clinically relevant ICH. Other concerns include potential drug interaction with 
chemotherapy and antiepileptic agents and the inability to measure the anticoagulant activity in daily practice (37). For these reasons, these agents cannot be currently advocated in neurooncology patients $(59,63)$. Further specific studies are needed.

Initial therapy should be initiated as early as possible, once contra-indications are ruled out, and should consist of LMWHs. $(37,41,43-44,59,61,64)$. A close monitoring in specific situations such as CNS malignancies, elderly patients and patients at high risk of bleeding, but no dose adjustment is recommended $(37,41,64)$.

\section{Duration of anticoagulation}

Duration of anticoagulation or secondary prophylaxis is an important topic because prevention of VTE recurrence may have a significant impact on the survival of cancer patients (65). This hypothesis relies on the observation that survival was significantly decreased in cancer patients with recurrent VTE, particularly when a pulmonary embolism occurred (65). The optimal duration of curative anticoagulation in cancer patients remains controversial. A minimum of 6 months of anticoagulation is commonly recommended. After 6 months, the decision to stop or continue anticoagulation should be based on an individual assessment of cancer activity, benefit-risk ratio, and patient preference. More often, it is recommended to prolong anticoagulation as long as the cancer is active and chemotherapy is administered, regardless of the risk of $\mathrm{ICH}$. In HGG patients, this means that most patients will receive an anticoagulant until the end of their life. Some of the guidelines allow for VKA replacement after 3 months with a targeted INR of 2 to 3 when LMWH is contraindicated or not available for any other reason including patient preference. In this situation, VKA should always be preferred to any new oral anticoagulant for the reasons mentioned above, and warfarin is the only VKA that has been extensively studied. 


\section{Management of TVP during bevacizumab administration}

Bevacizumab is a monoclonal antibody targeting vascular endothelial growth factor (VEGF) that has received FDA approval for recurrent GBM. Whether this agent increases the risk of venous thrombosis is still debated $(19,23)$. On other hand, a potential increase in the risk of ICH has initially raised great concern regarding the use of bevacizumab in this population. In GBM, the risk of ICH under bevacizumab is not significantly increased, with rates between $0 \%$ and $3.8 \%(66,67)$. For oligodendroglioma patients, who are slightly more prone to bleeding, a $24 \% \mathrm{ICH}$ rate has been reported under bevacizumab, but only $4 \%$ of patients were symptomatic and needed the treatment discontinued (68).

Uncertainties have also been raised regarding how to manage BT patients with a diagnosed VTE under bevacizumab. Few data (retrospective only) are available regarding the concomitant use of bevacizumab and anticoagulants at curative doses in GBM patients with a $\operatorname{VTE}(56,59,62)$. Nevertheless, the risk-to-benefit ratio seems to favor this combination despite an increased risk of $\mathrm{ICH}$ (from 3 to $11 \%)(56,69)$. Once the anticoagulation has been initiated at an effective dose, it is not clear how long bevacizumab should be interrupted before being reintroduced. 


\section{CONCLUSION}

Despite a high incidence of VTE and recurrent VTE in HGG patients, there is no standardized approach to the management of these patients, and many challenges remain. Nevertheless, most of the international recommendations for VTE in cancer patients can be applied, and some of those specifically address problems encountered in HGG. Nevertheless, a preassessment of the risk of $\mathrm{ICH}$ is advised prior to any treatment decision, and a close monitoring of these patients is advised. The duration of prophylaxis, and curative anticoagulation is an important matter that remains to be addressed because it may affect patients' survival. 


\section{KEY POINTS:}

- The presence of active intracranial symptomatic bleeding is an absolute contraindication to curative anticoagulation.

- Curative anticoagulation should be prescribed for a minimum of 6 months, then the decision to stop or continue anticoagulation should be based on cancer activity, performance status, benefit-risk ratio, and the patient's preference.

- LMWHs are preferred to other anticoagulants due to their excellent therapeutic index and lack of interaction with chemotherapy, steroids and antiepileptic agents.

- The concomitant use of bevacizumab and LMWHs at curative doses in GBM patients appears to be safe.

\section{Acknowledgments:}

No conflict of interest and no source of funding to declare for the 3 authors 


\section{REFERENCES:}

1. Mandel JJ, Yust-Katz S, Wu J, et al. Venous thromboembolism (VTE) and glioblastoma. J Clin Oncol 32:5s, 2014 (suppl; abstr 2033)

2. Edwin NC, Elson P, Ahluwalia MS, Khorana AA. Venous thromboembolism in patients with glioblastoma: Risk factors and prognostic importance. J Clin Oncol 33, 2015 (suppl; abstr e13027)

3. Edwin N, Khorana AA, Khoury M, et al. Venous thromboembolism in patients with glioblastoma multiforme. J Clin Oncol 32:5s, 2014 (suppl; abstr 2068)

4. Semrad TJ, O'Donnell R, Wun T, et al. Epidemiology of venous thromboembolism in 9489 patients with malignant glioma. J Neurosurg 2007; 106:601.

5. Smith TR, Nanney AD, Lall RR, et al. Development of venous thromboembolism (VTE) in patients undergoing surgery for brain tumors: results from a single center over a 10 year period. J Clin Neurosci. 2015;22(3):519-25.

6. Kayser-Gatchalian MC, Kayser K. Thrombosis and intracranial tumors. J Neurol $1975 ; 209: 217$

7. Simanek R, Vormittag R, Hassler M, et al. Venous thromboembolism and survival in patients with high-grade glioma. Neuro-Oncol 2007;9:89.

8. Jenkins EO, Schiff D, Mackman N, Key NS. Venous thromboembolism in malignant gliomas. J Thromb Haemost 2010; 8:221.

9. Marras LC, Geerts WH, Perry JR. The risk of venous thromboembolism is increased throughout the course of malignant glioma: an evidence-based review. Cancer. 2000; 89(3):640-6. 
10. Chaichana KL, Pendleton C, Jackson C, et al. Deep venous thrombosis and pulmonary embolisms in adult patients undergoing craniotomy for brain tumors. Neurol Res 2013;35(2):206-11.

11. Sawaya R, Auccarello M, Elkaliny M, Nishiyama H. Post operative venous thromboembolism and brain tumors: part 1- Clinical profile. J Neurooncol 1992; 14:119-25. 12. Brandes AA, Scelzi E, Salmistraro G, et al. Incidence of risk thromboembolism during treatment high-grade glioma: a prospective study. Eur J Cancer. 1997;33:1592-1596.

13. Anderson F, Huang W, Sullivan C, et al. The continuing risk of venous thromboembolism following operation for glioma: findings from the Glioma Outcomes Project. Thromb Hemost. 2001;86(Suppl):OC902 (abs)

*14. Dickinson H, Carico C, Nuño M, et al. Unplanned readmissions and survival following brain tumor surgery. J Neurosurg. 2015 ;122(1):61-8.

* A retrospective review of 362 cases involving patients with GBM undergoing biopsy or tumor resection reports that thromboembolic complications were accounting for $22 \%$ of unplanned readmissions within the 30 days of surgery.

15. Ruff RL, Posner JB. Incidence and treatment of peripheral venous thrombosis in patients with glioma. Ann Neurol 1983; 13:334.

16. Dhami MS, Bona RD, Calogero JA, Hellman RM. Venous thromboembolism and high grade gliomas. Thromb Haemost 1993; 70393-6.

17. Edwin NC, Elson P, Ahluwalia MS, Khorana AA. Venous thromboembolism in patients with glioblastoma: Risk factors and prognostic importance. J Clin Oncol 33, 2015 (suppl; abstr e13027)

18. Gerber DE, Grossman SA, Streiff MB. Management of venous thrombo-embolism in patients with primary and metastatic brain tumors.J Clin Oncol 2006;24:1310-1318. 
19. D'Agoretta D'Alpium Santos Costa D, Romeira D, Fernandes Valente M et al . Venous thrombotic events in patients with glioblastoma. J Clin Oncol 33, 2015 (suppl; abstr e13059) 20. Rodas RA, Fenstermaker RA, McKeever PE, et al. Correlation of intraluminal thrombosis in brain tumor vessels with post-operative thrombotic complications: a preliminary report. J Neurosurg 1998;89:200-205.

21. Prayson NF, Koch P, Angelov L, Prayson RA. Microscopic thrombi in anaplastic astrocytoma predict worse survival? Ann Diagn Pathol 2011;15(6):389-93.

22. Valladares JB, Hankinson J. Incidence of lower extremity deep vein thrombosis in neurosurgical patients. Neurosurgery 1980;6 :138-41.

23. Nalluri SR, Chu D, Keresztes R, et al. Risk of venous thromboembolism with the angiogenesis inhibitor bevacizumab in cancer patients: a metaanalysis. JAMA 2008; 300:2277-2285.

24. Misch M, Czabanka M, Dengler J, et al. D-dimer elevation and paresis predict thromboembolic events during bevacizumab therapy for recurrent malignant glioma. Anticancer Res. 2013;33(():2093-8.

**25. Thaler J, Ay C, Kaider A, et al. Biomarkers predictive of venous thromboembolism in patients with newly diagnosed high-grade gliomas. Neuro-Oncology 2014; 0, 1-7.

**In a prospective study, the authors identified biomarkers suitable for assessing the VTE risk in newly diagnosed HGG patients, they also identified high-risk and low-risk patients with 2 risk assessment models (RAMs).

26. Simanek R, Vormittag R, Ay C, et al. High platelet count associated with venous thromboembolism in cancer patients: results from the Vienna Cancer and Thrombosis Study (CATS). J Thromb Haemost 2010;8(1):114-120. 
27.Vormittag R, Simanek R, Ay C, et al. High factor VII levels independently predict venous thromboembolism in cancer patients: the cancer and thrombosis study. Arterioscler Thromb Vasc Biol 2009;29(12):2176-2181.

28.Zou JP, Morford LA, Chougnet C, et al. Human glioma-induced immunosuppression involves soluble factor(s) that alters monocyte cytokine profile and surface markers. $\mathrm{J}$ Immunol 1999;162(8):4882-4892.

29. Hamada K, Kuratsu J, Saitoh Y, et al. Expression of tissue factor correlates with grade of malignancy in human glioma. Cancer 1996;77:1877-1883.

30. Rong Y, Post DE, Pieper RO, Durden DL, , van Meir EG, Brat DJ. PTEN and hypoxia regulate tissue factor expression and plasma coagulation by glioblastoma. Cancer Res 2005;65:1406-1413.

31. Rong Y, Hu F, Mackman H, et al. Early growth response gene-1 regulates hypoxiainduced expression od tissue factor in glioblastoma multiforme through hypoxia-inducible factor-1 independent mechanisms. Cancer res 2006;66:7067-7074.

32. Blum S, Issbruker K, Willuweit A, et al. An inhibitory role of the phosphatidylinositol 3kinase signaling pathway in VEGF-induced tissue factor expression. J Biol Chem $2001 ; 276: 33428-33434$.

33. Skog J, Wurdinger T, van Rijn S, et al. Glioblastoma microvesicles transport RNA and proteins that promote tumor growth and provide diagnostic biomarkers. Nature Cell Biol $2008 ; 10: 1470-1476$.

34. Sartori MT, Della Puppa A, Balin A, et al. Prothrombotic state in glioblastoma multiforme: an evaluation of the procoagulant activity of circulating microparticles. $\mathbf{J}$ Neurooncol 2011; 104:225-231.

35. Thaler J, Ay C, Pabinger I. Clinical significance of circulating microparticles for venous thromboembolism in cancer patients. Hamostaseologie. 2011;32(2):127-131. 
36.Thaler J, Ay C, Mackman N, et al. Microparticle-associated tissue factor activity, venous thromboembolism and mortality in pancreatic, gastric, colorectal and brain cancer patients. J Thromb Haemost 2012;10(7):1363-1370.

37. Lyman GH, Khorana AA, Kuderer NM, et al. Venous Thromboembolism Prophylaxis and Treatment in Patients with Cancer: American Society of Clinical Oncology Practice Guideline Update. Journal of Clin Oncol 2013;31(17):2189-2204.

38. Khorana AA, Kuderer NM, Culakova E, et al. Development and validation of a predictive model for chemotherapy-associated thrombosis. Blood 2008;111:4902-4907.

39. Verso M, Agnelli G, Barni S, et al.A modified Khorana risk assessment score for venous thromboembolism in cancer patients receiving chemotherapy: the Protecht score. Intern Emerg Med 2012;7:291-292.

40. Ay C, Dunkler D, Marosi C, et al. Prediction of venous thromboembolism in cancer patients. Blood 2010;116:5377-5382.

41. Lyman GH, Khorana AA, Falanga A, et al. American Society of Clinical Oncology Guideline: recommendations for venous thromboembolism prophylaxis and treatment in patients with cancer. J Clin Oncol 2007;25(34):1-16

42. Farge D, Debourdeau P, Beckers M, et al. International clinical practice guidelines for the treatment and prophylaxis of venous thromboembolism in patients with cancer.

J Thromb Haemost. 2013 ;11(1):56-70

43. Mandala M, Falanga A, Piccioli A, et al. Venous thromboembolism and cancer: guidelines of the Italian Asssociation of Medical Oncology (AIOM). Crit Rev Oncol Hematol 2006; 59:194-204.

44. Mandala M, Falanga A, Roila F: Management of venous thromboembolism in cancer patients: ESMO clinical recommendations. Ann Oncol 2008 ; 19 (suppl 2) :ii126-127. 
*45. Frisisus J, Ebeling M, Karst M, et al. Prevention of venous thromboembolic complications with and without intermittent pneumatic compression in neurosurgical cranial procedures using intraoperative magnetic resonance imaging. A retrospective analysis.

Clinical neurology and neurosurgery. $2015 ; 133$ :46-54.

* This retrospective analysis of 207 neurosurgical patients shows the benefit of pneumatic compression preventing thromboembolic complications.

46. Agnelli G, Piovella F, Buoncristiani P, et al. Enoxaparin plus compression stockings compared with compression stockings alone in the prevention of venous thromboembolism after elective neurosurgery. N Engl J Med 1998; 339:80.

47. Constantini S, Kanner A, Friedman A, et al. Safety of perioperative minidose heparin in patients undergoing brain tumor surgery: a prospective, randomized, double-blind study. J Neurosurg 2001; 94:918.

48. Iorio A, Agnelli G. Low-molecular-weight and unfractionated heparin for prevention of venous thromboembolism in neurosurgery: a meta-analysis. Arch Intern Med 2000; 160:2327. 49. Dickinson LD, Miller LD, Patel CP, Gupta SK. Enoxaparin increases the incidence of postoperative intracranial hemorrhage when initiated preoperatively for deep venous thrombosis prophylaxis in patients with brain tumors. Neurosurgery 1998; 43:1074. *50.Lukassen J NM, Groen J L,Jacobs WC and Vleggeert-Lankamp C LA. Thromboembolic Prophylaxis in Neurosurgical Practice: A Review. J Spine 2014, 4:1

*This systematic review of the literature reports that an optimal antithrombotic prophylaxis, based on a combination of LMWH and compression stockings, in intracranial interventions lowers the incidence of VTE from $28 \%$ to about 3 to $6 \%$.

51. Perry JR, Julian JA, Laperriere NJ, et al. PRODIGE: a randomized placebo-controlled trial of dalteparin low-molecular-weight heparin thromboprophylaxis in patients with newly diagnosed malignant glioma. J Thromb Haemost 2010; 8:1959. 
52. Robins HI, O'Neill A, Gilbert M,et al. Effect of dalteparin and radiation on survival and thromboembolic events in glioblastoma multiforme: a phase II ECOG trial. Cancer Chemother Pharmacol. 2008 ;62(2):227-33.

53. Perry SL, Bohlin C, Reardon DA, et al. Tinzaparin prophylaxis against venous thromboembolic complications in brain tumor patients. J Neurooncol 2009; 95:129.

54. Kuhn S A, Marosi C, Pabinger I,et al. CoaGlio IV Trial: Randomized, controlled, tripleblind, multinational phase III study of adjuvant prophylactic anticoagulation in patients with glioblastoma WHO IV. J Clin Oncol 2015 ;33 : (suppl; abstr TPS2079)

55. Quevedo JF, Buckner JC, Schmidt JL, et al. Thromboembolism in patients with highgrade glioma. Mayo Clin Proc 1994; 69:329.

56. Perry JR. Anticoagulation of malignant glioma patients in the era of novel antiangiogenic agents. Curr Opin Neurol 2010;23:592-596.

57. Bitoh S, Hasegawa H, Ohtsuki H, Obashi J, Fujiwara M, Sakurai M. Cerebral neoplasms initially presenting with massive intra-cerebral hemorrhage. Surg Neurol 1984;22:57-62 58. Lieu AS, Hwang SL, Howng SL, Chai CY. Brain tumors with hemorrhage. J Formos Med Assoc 1999;98:365-7.

59. Perry JR. Thromboembolic disease in patients with high-grade glioma. Neuro-Oncology 2012; $14: 73-80$.

60. Vitale FV, Rotondo S, Sessa E, Parisi A, et al. Low molecular weight heparin administration in cancer patients with hypercoaguability-related complications and carrying brain metastases: a case series study. J Oncol Pharm Pract 2012;18(1):10-6.

61. Lee A YY, Levine MN, Baker RI, et al. Low-Molecular-Weight Heparin versus a Coumarin for the Prevention of Recurrent Venous Thromboembolism in Patients with Cancer ,N Engl J Med 2003; 349:146-153 
62. Levin JM, Schiff D, Loeffler JS, et al. Complications of therapy for venous thromboembolic disease in patients with brain tumors. Neurology 1993; 43:1111. 63. Jo JT, Schiff D, Perry JR. Thrombosis in brain tumors. Semin Thromb Hemost 2014;40(3):325-31.

64. Khorana AA, Streiff MB, Farge D, et al. Venous Thromboembolism Prophylaxis and Treatment in Cancer: A Consensus Statement of Major Guidelines Panels and Call to Action. J Clin Oncol 2009;27:4919-26

65. Chee CE, Ashrani AA, Marks RS et al. Predictors of venous thromboembolism recurrence and bleeding among active cancer patients: a population-based cohort study. Blood 2014; 123(25):3972-8

66. Kreisl TN, Kim L, Moore K, et al. Phase II trial of single-agent bevacizumab followed by bevacizumab plus irinotecan at tumor progression in recurrent glioblastoma. J Clin Oncol $2009 ; 27: 740$.

67. Friedman HS, Prados MD, Wen PY, et al. Bevacizumab alone and in combination with irinotecan in recurrent glioblastoma. J Clin Oncol 2009; 27:4733.

68. Taillibert S, Vincent LA, Granger B, et al. Bevacizumab and irinotecan for recurrent oligodendroglial tumors. Neurology. 2009 May 5;72(18):1601-6.

69. Norden AD, Bartolomeo J, Tanaka S, et al. Safety of concurrent bevacizumab therapy and anticoagulation in glioma patients. J Neurooncol 2012; 106:121.

70. Lee A, Kastelan M, and Wheeler H. Use of bevacizumab in anticoagulated recurrent glioblastoma multiforme patients: an Australian experience. Ann Oncol (2014) 25 (suppl 4): iv144, 435P. 